\title{
Research on the cultivation strategy of critical thinking of medical doctoral students based on constructivism learning theory
}

\section{Yan Wu ( $\square$ wuyan@wchscu.cn )}

Sichuan University West China Hospital

\section{Ling-Ying Wang}

Sichuan University West China Hospital

\section{Guan-Nan Huo}

Sichuan University West China Hospital

Chang Xu

Sichuan University West China Hospital

Xing-Yue Wang

Sichuan University West China Hospital

\section{Research article}

Keywords: Medicine, Doctoral students, Critical thinking, Constructivism learning theory

Posted Date: January 22nd, 2020

DOI: https://doi.org/10.21203/rs.2.21525/v1

License: (c) (i) This work is licensed under a Creative Commons Attribution 4.0 International License. Read Full License 


\section{Abstract}

Background: Critical thinking (CT) is the logical beginning of innovative thinking. Especially for medical doctoral students, critical thinking enables them to apply flexibly existing experience and knowledge to make reasonable judgments and optimal decision through analysis and reasoning on the basis of reflection in the complex clinical situations. The present study aimed to investigate the current situation of critical thinking of medical doctoral students, and was performed to attribute the factors of critical thinking and optimize the relationship between educational goals and higher-level talents, to formulate a CT training strategy for medical doctoral students based on constructivism learning theory.

Methods: A cross-sectional survey of critical thinking was conducted among 343 medical doctoral students from 8 universities by using the Chinese version of the Critical Thinking Ability Scale. SPSS 22.0 statistical software was used to establish database and analyze data.

Results: The average score of critical thinking ability of 343 medical doctoral students was 292.43 , and the score of truth-seeking in seven traits was lower than the minimum recognition score of 40 . Extroverted medical doctoral students scored higher than those introverted in the traits of critical thinking, systematicity, self-confidence and inquisitiveness $(P<0.05)$. Medical doctoral students with reading habits scored higher than those without reading habit in the traits of total score of critical thinking, open-thinking, analyticity, systematicity, self-confidence, inquisitiveness and maturity $(P<0.05)$. There were statistically significant differences in the total score of critical thinking, open-thinking, analyticity, systematicity, self-confidence, inquisitiveness and maturity in medical doctoral students with different interpersonal relations $(P<0.05)$. Linear regression analysis found that the personality, reading habits, parental education and critical thinking of medical doctoral students were significantly correlated $(P<0.05)$.

Conclusions: 343 medical doctoral students generally have positive critical thinking personality, but the honesty and objectivity of seeking truth are not enough. It is necessary to actively guide students to participate in extracurricular practice and improve their ability of maintaining interpersonal relationships, cultivate students' active reading habits and pay attention to the cooperative education mechanism of tutors, counselors and ideological and political teachers in the process of education, so as to promote students' critical thinking and allround development.

\section{Background}

Critical thinking (CT) is the logical beginning of innovative thinking ${ }^{[1]}$, which has already been enrolled in American education reform in the 1940s. In 1970s, critical thinking had begun to be written into educational and teaching objectives gradually in America, Britain and Canada. Moreover, by 1990s, the International Interdisciplinary Research Project reached a consensus on critical thinking education through six rounds of consultation with Delphi method ${ }^{[2]}$. The consensus included the purposeful self-regulation and developing the habits of habitual questioning, introspection, careful judgment, objectivity, fairness and creativity ${ }^{[3,4]}$. In the Guidelines of the National Program for Medium- and Long-Term Educational Reform and Development (2010-2020), it emphasized that improving the quality of graduate students, especially the innovation ability of doctoral students, is quite important for cultivating of top-notch innovative talents. Constructivism perspective emphasizes the meaningful learning, the learners should regard the original knowledge as a new growing point of following knowledge, and be able to understand and elaborate things or show introspection in their own way. 
The stage of doctoral education is a transition from "the certainty of ignorance " to "the confusion of knowledge", using CT to decide what to believe or what to do and constructing a new knowledge structure through reflective and reasonable thinking mode ${ }^{[5]}$. The cultivation of top-notch innovative talents should be planned as soon as possible to promote the practical study of scientific research and the improvement of $\mathrm{CT}^{[6]}$. During the medical practice, medical staff can make the best decisions among all sorts of choice when they face with problems in complex situations ${ }^{[7]}$. In the national strategies of "innovation-driven development", medical doctoral students are the driving force of innovation and development. CT is essential for both making sustainable contribution of scientific and technological innovation in the future and making right decisions in a wide range of complex clinical scenarios.

\section{Methods}

\subsection{Aims of the present study}

The present study aimed to investigate the current situation of CT among the medical doctoral students enrollment nationwide by conducting a questionnaire survey, and explore its relevant factors from the perspective of constructivism, so as to provide valuable reference data for CT training and improve education methods.

\subsection{Study design}

A professional online platform powered by www.wjx.cn was adopted to issue and collect the investigation from March 2019 to April 2019. A total of 343 medical doctoral students in three grades from Sichuan University, Fudan University, Shanghai JiaoTong University, Shandong University, Xiamen University, Central South University, Nanjing Medical University and Jinan University participated in this study. Each university has a contact person who is responsible for the investigation. According to the purpose of the study and follow the principle of voluntary participation, this study formulated three selection criteria: (1) Doctoral candidate, (2) No cognitive or mental disorder, (3) Voluntary participation.

\subsection{Data collection}

The following information were collected from the candidates: gender, age, marital status, academic type, scientific research practice (articles published, participation in research subject, patent application, book compilation and so on), understanding degree of critical of thinking, etc. Each item in the investigation is required to fill in and so that the questionnaires collected finally should be all submitted successfully.

\subsection{Questionnaires}

The Chinese Version of Critical Thinking Disposition Inventory (CTDI-CV) questionnaire was used to assess the level of critical thinking for medical students. This instrument was developed by Facione ${ }^{[8]}$, and revised by Peng ${ }^{[9]}$. It contains 7 traits that covering a wide range of the ability which were: truth-seeking, open-thinking, analyticity, systematicity, self-confidence, inquisitiveness and maturity. Using Likert 6-level scoring method, positive items were assigned 1-6 points from very disagree to very agree, and negative items were scored in reverse. The total score of the scale is $70-420$ scores, $<280$ scores indicating weak critical thinking ability, $280-349$ scores indicating positive critical thinking ability, and $\geq 350$ scores indicating strong critical thinking ability. The total score of each dimension is 10-60 scores, of which 30-39 scores indicates that the trait is in the middle level, $40-49$ scores indicates that the trait is positive, and $\geq 50$ scores indicates that the trait is strong. The content validity index of the total scale is 0.89 , and the chronbach's a coefficient of the total scale is $0.90^{[6]}$.

\subsection{Statistical analysis}


The present study summarized the baseline characteristic by descriptive statistics. In detail, for continuous variable, the mean for median value was used to reflect the statistic information and discrete variable, the proportion in each category were calculated.

In order to investigate the potential prediction factors for the critical thinking score, this study pre-defined 7 traits which were documented by previous researches. Those were: truth-seeking, open-thinking, analyticity, systematicity, self-confidence, inquisitiveness and maturity. An univariable simple linear regression model was first established for these variables against the total score to see if these variables were associated with the score; then a multivariable linear regression that considering the potential correlations among these variables was conducted for those variables significantly associated with the score. It was conducted by the weighted least square regression with robust variance as an attempt to improve the point and variance estimation.

All of the analysis was archived by SPSS 22.0 statistical software. And alpha $=0.05$ was treated as statistically significant level.

\section{Results}

\subsection{Baseline characteristics}

A total of 343 valid questionnaires were collected, and the general demographic data is shown in Table 1. Among them, $57.7 \%$ medical doctoral students belong to the type of academic degree, $58.3 \%$ medical doctoral students are female, the majority of them are $26-30$ years old $(71.1 \%), 51.0 \%$ of medical doctoral students are non-only children, $81.0 \%$ medical doctoral students have reading habits, $51.9 \%$ of medical doctoral students could cope with complex interpersonal relationships, and $69.1 \%$ medical doctoral students have no work experience. They have different levels of scientific research practice: published articles (69.4\%), participation in the project (88.0\%), patent application (7.3\%), and book compilation (19.2\%).

\subsection{Distribution trend of critical thinking of medical doctoral students}

\subsubsection{Scores of critical thinking of medical doctoral students}

The lowest scores, the highest scores, the mean scores and standard deviation of the seven traits and the total sore of critical thinking are shown in Table 2. The total score of critical thinking of 343 medical doctoral students is more than 280 , indicating that they have positive critical thinking ability as a whole. In addition to the score of truthseeking is lower than the minimum recognition score of 40 , the scores of the other six characteristics are higher than 40 , and the scores from high to low are inquisitiveness, analyticity, maturity, open-thinking, systematicity and self-confidence.

\subsubsection{The total score of CT and the ratio of high and low scores of 7 traits}

The total score of critical thinking which is lower than 280 is defined as low scores, and greater than 350 is defined as high scores; the scores of traits which are lower than the minimum recognition score of 40 are regarded as low scores, and scores greater than 50 are regarded as high scores. The number and composition ratio of the total score and traits of critical thinking in 343 medical doctoral students are shown in Table 3.

\subsection{Personality and critical thinking ability}


Compared with introverted medical doctoral students, extroverted medical doctoral students had significant differences in the total scores of critical thinking and the scores of systematicity, self-confidence, and inquisitiveness $(P<0.05)$, as shown in Table 4.

\subsection{Reading habits and critical thinking ability}

Compared with medical doctoral students without reading habit, there were significant differences in the total scores of critical thinking and the scores of open-thinking, systematicity, self-confidence, inquisitiveness and maturity in medical doctoral students with reading habit, as shown in Table 5.

\subsection{Interpersonal relations and critical thinking ability}

According to the analysis of variance, there were statistically significant differences in the total score of critical thinking and the scores of open-thinking, analyticity, systematicity, self-confidence, inquisitiveness and maturity in medical doctoral students with different interpersonal relations, as shown in Table 6.

SNK-q test (native function in SPSS 22.0 ) indicated that medical doctoral students with quite difficult interpersonal relation got lower scores in the total scores of critical thinking and the scores of analyticity, systematicity and selfconfidence, compared with medical doctoral students with quit easy, easy and deal with interpersonal relations. Medical doctoral students with quite difficult interpersonal relation had lower scores in open-thinking than medical doctoral students with easy and deal with interpersonal relations. Medical doctoral students with quite difficult interpersonal relation had lower scores in inquisitiveness than medical doctoral students with very easy and deal with interpersonal relations. Medical doctoral students with quite difficult interpersonal relation had lower scores in maturity than medical doctoral students with easy, deal with and difficult interpersonal relations. Medical doctoral students with quit easy interpersonal relation had higher scores in analyticity, systematicity and maturity than medical doctoral students with deal with and difficult interpersonal relations.

\subsection{Related factors of critical thinking scores}

Through linear regression analysis, the study indicated that the character, reading habits of the medical doctoral student, education level of their parents are significantly correlated with critical thinking. The critical thinking scores of extroverted medical doctoral students are significantly higher than the introverted students, and the higher the education level of parents, the more extracurricular reading time, result in the higher score of critical thinking. At the same time, gender, work experience, academic type, and domicile status were not significantly associated with critical thinking scores. As shown in Table 7.

\section{Discussion}

CT influences the quality of scientific research and innovation of medical doctoral students. The cultivation of medical doctoral students in a university should comply with the regularity of the individual growth. The current domestic education environment of memory type, force-feeding teaching ways and unidirectional evaluation method limits the development and independent construction of $\mathrm{CT}^{[10]}$. The general mode of medical doctoral students' education is teaching mentoring relationship, where personal cultivation characteristics are quite outstanding. Therefore, how to put forward suitable CT training strategy to promote and develop CT of medical doctoral students has become an urgent problem in the graduate students' education to break through the thinkingset and promote all-around development and innovation of medical doctoral students. 


\subsection{Create a thinking education culture and environment}

Culture has a certain impact on people's thinking concepts, values and attitudes. Traditional culture pays attention to obedience to authority and has certain restrictions on individual thoughts ${ }^{[11]}$. The traditional teacher-centered classroom atmosphere, "cramming" teaching methods and exam-oriented education have made students no longer interested in looking for the truth. If things continue this way, students' overall ability of analyzing problems systematically and independently as well as their spirit of introspection, questioning and criticism will be greatly constrained ${ }^{[12]}$. The cultural environment of colleges affects students' "acculturation", and different college cultures have different influences on students ${ }^{[13]}$. The development of CT needs not only the active and independent construction of individuals, but also the value guidance and help of the educational environment. The results showed that the average score of CT among the enrolled 343 medical doctoral students is 292.43 scores, which is higher than 280 scores, indicating that these students have positive CT characters. Compared with the domestic surveys on CT ability of medical undergraduates ${ }^{[14]}$, the CT ability of medical doctoral students is positively improved than that in the undergraduate stage. The main reason is that the teaching-mentoring teaching environment and the arrangement of different levels of scientific research training, including publishing articles and participating in projects, encourage and support doctors to try CT and participate in critical discussions.

In the present research, among the 7 traits, the highest score of inquisitiveness indicates that medical doctoral students have great potential in acquiring professional knowledge, clinical skills and scientific research ability. However, in terms of truth-seeking, the score is lower than the minimum recognition score of 40 , which indicates that medical doctoral students are not honest and objective enough in seeking for true knowledge, and the passive acceptance of knowledge is relatively significant, which may be related to the cultural background and traditional education mode that make students accustomed to passive acceptance of knowledge. To create the atmosphere of thinking education culture requires doctoral supervisors to help build a democratic and open teaching relations actively, with the attitude of equality, tolerance and dialectics to promote the awakening of CT subject. By forming sparks of thought in the collision of dialogues and interactive discussions, and building the psychological development through experiences from confusion to be suddenly enlightened, they will provide the possible space for the development of CT.

This study regarded the total CT score of 280 points and 350 points as the judgment criteria of the normal ability and strong ability of positive CT personality respectively, additionally, score of traits of 40 points and 50 points as the judgment criteria of the minimum recognition score and strong ability respectively. The present study revealed that among the 343 medical doctoral students, $67.6 \%$ had positive CT personality, while only $1.2 \%$ of them had strong CT ability. Besides, among the seven traits, $19.0 \%$ and $12.2 \%$ of the medical doctoral students showed strong inquisitiveness and analytical skills, while $58.6 \%, 43.7 \%$ and $41.7 \%$ of them did not reach the minimum recognition scores in truth-seeking, self-confidence and systematicity respectively. The results demonstrated that the enrolled medical doctoral students have a strong inquisitiveness, great potential to acquire professional knowledge, clinical practice skills and scientific research ability, and they can look for key points to solve problems actively. But their ability of truth-seeking, self-confidence and systematicity, need to be further strengthened.

As a practical discipline, medicine is undergoing the transformation from basic science to humanistic society ${ }^{[15]}$. The new curriculum system must adapt to the needs of social development and set educational goals to understand diseases and health from the comprehensive variables of society, culture, psychology, environment and an even broader background. Educators are suggested to combine with the educational goals of the subjects, set 
up systematic module learning, academic discussions, clinic training, bedside teaching, et al, and promote the development of cognitive skills of CT comprehensively through diversified teaching strategies such as small class teaching, student centered teaching, reading and writing ability strengthened teaching, and participation of classroom interaction stimulated teaching. Only when the seven traits of CT are improved collectively, can individuals skillfully apply CT skills in their personal study, work and life ${ }^{[16,17]}$.

\subsection{Guide the emotional tendency of critical thinking}

The present study revealed that extroverted medical doctoral students scored higher than introverted students on total score, systematicity, self-confidence and inquisitiveness, which was consistent with the investigation of Bao et

al ${ }^{[12]}$. In addition, scores of critical thinking, open-thinking, analyticity, systematicity, self-confidence, inquisitiveness and maturity also revealed significant differences among medical doctoral students with different coping styles of complex interpersonal relationships, which was consistent with the investigation of Tang et al ${ }^{[18]}$. Students who are able to navigate complex interpersonal relationships tend to score higher on CT scores. It is very important for a medical worker to be realistic, independent, persistent, enthusiastic and unafraid of authority in the complex working environment ${ }^{[19]}$.

Extroverted students tend to be more willing to participate in extracurricular activities, and are good at communicating with people in the activities. They are always active and agile. Such personality characteristics will also enable students to show more subjective initiative in teamwork, which will benefit their scientific research and future work as well ${ }^{[20]}$. On the contrary, students whose interpersonal relationship is in a mess are relatively weak in $\mathrm{CT}$, which should arouse special attention and guidance from educators. Educators can help students to be more active in activities or classes by strengthening social activities and conversational teaching mode, thus help them to be more talkative and promote the improvement of interpersonal relations. Dialogue teaching encourages students to question and criticize others' opinions, put forward their own unique opinions, dilute the authority of books and teachers, and create a relaxed academic atmosphere in which all students participate in as much as possible. It is even more essential for medical students to learn to get along pleasantly with others. If the daily interpersonal relationship is in a mess, then doctor-patient communication will become a major obstacle to a doctor's development ${ }^{[19]}$. On the other hand, educators should guide students participate in the debates, brainstorming, conscience examining and other activities, add CT cultivation concept in the disciplines and professional education and include interpersonal relationship, mental health, professional quality in the comprehensive quality education courses to allow students of different personality traits to gain the ability to solve realistic problems and the emotional tendencies of critical thinking in an inclusive culture of universities and in real life and clinical scenes. It is a compulsory course for medical educators to respect students' personality traits and guide on their emotional tendency.

\subsection{Optimize the training strategy of critical thinking of doctoral students}

The present study investigated the general demographic characteristics, personality, gender, age, marital status, academic type and scientific research of medical doctoral students. The present study found that personality, extracurricular reading, and parents' education were significantly correlated with CT. In terms of personality, introverted students scored significantly lower than extroverted students in $\mathrm{CT}(\mathrm{B}=-7.28,95 \% \mathrm{Cl}=[-13.02,-1.53], \mathrm{P}=$ 0.013). And in regard to reading habits, compared with students without reading habits, students with reading habits scored significantly higher in $\mathrm{CT}$, and the scores increased as the reading time increased $(\leq 7 \mathrm{~h}$ : $B=10.57$, 
$95 \% \mathrm{Cl}=[3.02,17.96], \mathrm{P}=0.006 ; 7-14 \mathrm{~h}: \mathrm{B}=15.80,95 \% \mathrm{Cl}=[6.92,24.69], \mathrm{P}=0.001 \rrbracket \geq 14 \mathrm{~h}: \mathrm{B}=21.15,95 \% \mathrm{Cl}=[12.58$, 29.71], $P \otimes 0.001$ ). Additionally, the highest educational level of parents is positively correlated with CT of students. Students whose parents' highest educational level were under bachelor's degree scored lower on CT tests when compared to those whose parents had advanced degrees (master's degree or higher) (bachelor /junior college: $\mathrm{B}=$ $-14.69,95 \% \mathrm{Cl}=[-29.12,-0.71], \mathrm{P}=0.046$; senior high school: $\mathrm{B}=-12.38,95 \% \mathrm{Cl}=[-27.58,2.81], \mathrm{P}=0.11$; junior high school or less: $\mathrm{B}=-15.39,95 \% \mathrm{Cl}=[-30.56,-0.21], \mathrm{P}=0.047)$.

Scores of critical thinking, analyticity, systematicity, self-confidence, inquisitiveness and maturity among medical doctoral students with reading habits were significantly higher than those without reading habits, which was consistent with the study of Xie et al ${ }^{[21]}$. Those without reading habits scored even less than the minimum recognition scores (40 points) in truth-seeking, systematicity and self-confidence. Reading is a kind of intelligent activity. People who read a lot have richer indirect experience toward the world, and their emotions are more delicate and sensitive. Their thinking level will be improved day by day as well ${ }^{[22]}$. Extracurricular reading can broaden one's horizon, improve students' imagination and creativity, and promote the ability of summarizing knowledge.

Educators should guide students to develop a good daily quantitative reading habit, and encourage students to find problems and raise questions while reading. For instance, students may read references related to the subject research and attend classes like small lectures and TBL team-based teaching classes ${ }^{[23]}$. During these learning process, they are encouraged to propose pertinent and relevant questions about a specific topic and express their views confidently and clearly in the discussion. Through these methods, educators will be able to guide medical students to construct new knowledge and experience from the original ones. Lastly, although it seems that parents' academic qualifications cannot be changed, this result indirectly reflects the important role of higher education in the formation of CT. By establishing a good interpersonal communication circle of high-level talents, it is expected

to have a positive effect on the further formation of students' CT. Only by promoting the above positive factors and reducing the negative factors, can the cultivation strategy of CT of medical talents be continuously optimized.

\section{Conclusions}

343 medical doctoral students generally have positive critical thinking personality, but the honesty and objectivity of seeking truth are not enough. It is necessary to guide students to improve their ability of maintaining interpersonal relationships and cultivate students' active reading habits to promote students' critical thinking and all-round development.

Although the present study was carried out nationwide, the number of returned questionnaires was limited, which made the research results representative but limited in extension. The study will continue to conduct multi-center cooperation to make contributions to the development of a complete CT training system for medical doctoral students in further investigations.

\section{Declarations}

\section{Ethics approval and consent to participate}

This research was approved by the Institutional Review Boards of the Ethics Committee of West China Hospital of Sichuan University. Participants were informed of the purpose of the investigation and informed consent was obtained from all participants before being enrolled. 
Consent for publication

Not applicable.

\section{Availability of data and materials}

The data used and/or analyzed during the current study are available from the corresponding author on reasonable request.

\section{Competing interests}

The authors declare that they have no competing interests.

\section{Funding}

Not applicable.

\section{Authors' contributions}

Yan Wu and Lingying Wang contributed to the design and collection of the questionnaires. Lingying Wang was responsible for the data interpretation. Yan Wu contributed to draft the manuscript, and Guannan Huo and Chang Xu were major contributors in professional organising and writing the manuscript. Xingyue Wang was responsible for manuscript revision and was the corresponding author. All authors read and approved the final manuscript.

\section{Acknowledgements}

The authors are grateful to the staff of the Fudan University, Shanghai JiaoTong University, Shandong University, Xiamen University, Central South University, Nanjing Medical University and Jinan University participated in this study, who provided accesses to issue the questionnaires.

\section{Abbreviations}

CT: critical thinking;

TBL: team-based teaching;

CTDI-CV: Critical Thinking Disposition Inventory

\section{References}

1. Zhang M, Yin Y. Critical Thinking: The Key to Innovation for Graduate Students. Xue Wei Yu Yan Jiu Sheng Jiao Yu. 2011(9):29-32.

2. Chen B. Critical Thinking and Innovative Talent Training. Zhongguo Da Xue Jiao Xue. 2017(3):22-28.

3. Staib S. Teaching and Measuring Critical Thinking. J Nurs Educ. 2003;42(11):498-508.

4. Zuriguel Pérez E, Lluch Canut MT, Falcó Pegueroles A, Puig Llobet M, Moreno Arroyo C, Roldán Merino J. Critical Thinking in Nursing: Scoping review of the literature. Int J Nurs Pract. 2015;21(6):820-30.

5. Feng K, Su YP. Brief Probe into Evidence-based Medical Thinking and Innovation of Medical Education. Ke Jiao Wen Hui. 2014(6): 70-71. 
6. Xie B, Liu B, Liu F, Xu XL. Problem-based learning (PBL) helpful to critical thinking skills of medical students in military medical college. Zhongguo Gao Deng Yi Xue Jiao Yu. 2012(3): 130-132.

7. Foster JS, Lemus JD. Developing the critical thinking skills of astrobiology students through creative and scientific inquiry. Astrobiology. 2015;15(1): 89-99.

8. Facione PA, Facione NC. The California Critical Thinking Disposition Inventory (CCTDI). Test Administration Manual. Millbrae, CA: California Academic Press, 1992.

9. Peng MC, Wang GC, Chen JL, Chen MH, Bai HH, Li SH, et al. Validity and Reliability of the Chinese Critical Thinking Disposition Inventory. Zhonghua Hu Li Za Zhi. 2004;39(9): 644-647.

10. Xiao WW. Educational reflection and cultivation strategy of critical thinking deficiency. Zhongguo Jiao Yu Xue Kan. 2015(1):25-29.

11. Chen YC. Chinese values, health and nursing. J Adv Nurs. 2001;36(2):270-3.

12. Bao L, Zhang YQ, Chen Y, Wu P, Li LS. Analysis on Current Status and Related Factors of Critical Thinking Ability in Nursing and Medical Undergraduates. Jie Fang Jun Hu Li Za Zhi. 2010;27(18): 1369-1372.

13. Mercado A, Ramirez M, Sharma R, Popan J, Avalos Latorre ML. Acculturation and substance use in a Mexican American college student sample. J Ethn Subst Abuse. 2017;16(3):276-292.

14. Wu H, Bai L, Yao YX, Liang YQ, Qiu YQ, Zhao YG, et al. Investigation and Analysis of 327 Medical Students' Critical Thinking Ability. Zhongguo Wei Sheng Chan Ye. 2018;15(15),175-176.

15. Visser CLF, Ket JCF, Croiset G, Kusurkar RA. Perceptions of residents, medical and nursing students about Interprofessional education: a systematic review of the quantitative and qualitative literature. BMC Med Educ. 2017;17(1):77.

16. Gleason BL, Gaebelein CJ, Grice GR, Crannage AJ, Weck MA, Hurd P, et al. Assessment of students' criticalthinking and problem-solving abilities across a 6-year doctor of pharmacy program. Am J Pharm Educ. 2013;77(8):166.

17. Jaffe LE, Lindell D, Sullivan AM, Huang GC. Clear skies ahead: optimizing the learning environment for critical thinking from a qualitative analysis of interviews with expert teachers. Perspect Med Educ. 2019 Sep 27; doi: 10.1007/s40037-019-00536-5.

18. Tang WJ. Associations between critical thinking ability and work pressure of nurses in secondary hospitals. Te Bie Jian Kang. 2017(14):15-16.

19. Gupta M, Upshur R. Critical thinking in clinical Medicine: what is it?. J Eval Clin Pract. 2012;18(5):938-944】

20. Rodriguez KD, Bartoloni JA, Hendricson WD. Is Dental Students' Clinical Productivity Associated with Their Personality Profile?. J Dent Educ. 2017;81(12):1436-1443.

21. Xie ZF, Cao W, Zhang WP, Zhu HY, Hu YP. Critical thinking dispositions and related factors among medical undergraduates. Zhongguo Gao Deng Yi Xue Jiao Yu. 2014(10): 31-32.

22. Watson EM. The importance of leisure reading to health sciences students: results of a survey. Health Info Libr J. 2016;33(1):33-48.

23. Moon H, Hyun HS. Nursing students' knowledge, attitude, self-efficacy in blended learning of cardiopulmonary resuscitation: a randomized controlled trial. BMC Med Educ. 2019;19(1):414.

\section{Tables}

Table 1 Baseline characteristics of 343 medical doctoral students 


\begin{tabular}{|c|c|c|c|c|c|}
\hline $\begin{array}{l}\text { Baseline } \\
\text { characteristics }\end{array}$ & Context & $\begin{array}{l}\text { Number } \\
\text { (Ratio) }\end{array}$ & $\begin{array}{l}\text { Baseline } \\
\text { characteristics }\end{array}$ & Context & $\begin{array}{l}\text { Number } \\
\text { (Ratio) }\end{array}$ \\
\hline \multirow[t]{2}{*}{ Academic type } & $\begin{array}{l}\text { Professional } \\
\text { degree }\end{array}$ & $145(42.3)$ & $\begin{array}{l}\text { Interpersonal } \\
\text { relations }\end{array}$ & Very easy & $17(5.0)$ \\
\hline & $\begin{array}{l}\text { Academic } \\
\text { degree }\end{array}$ & $198(57.7)$ & & Easy & $178(51.9)$ \\
\hline \multirow[t]{2}{*}{ Gender } & Male & $143(41.7)$ & & Deal with & $107(31.2)$ \\
\hline & Female & $200(58.3)$ & & Difficult & $35(10.2)$ \\
\hline \multirow[t]{4}{*}{ Age } & $20-25$ & $21(6.1)$ & & Quite difficult & $6(1.7)$ \\
\hline & $26-30$ & $244(71.1)$ & $\begin{array}{l}\text { Publish research } \\
\text { paper }\end{array}$ & Yes & $238(69.4)$ \\
\hline & $31-35$ & $54(15.7)$ & & No & $105(30.6)$ \\
\hline & $\geq 35$ & $24(7.0)$ & Research subject & Yes & $302(88.0)$ \\
\hline \multirow[t]{2}{*}{ One-child } & Yes & $168(49.0)$ & & No & $41(12.0)$ \\
\hline & No & $175(51.0)$ & Registered patent & Yes & $25(7.3)$ \\
\hline \multirow[t]{2}{*}{ Marital status } & Married & $152(44.3)$ & & No & $318(92.7)$ \\
\hline & Unmarried & $191(55.7)$ & Academic book & Yes & $66(19.2)$ \\
\hline \multirow[t]{2}{*}{ Domicile } & City & $233(67.9)$ & & No & $277(80.8)$ \\
\hline & Rural & $110(32.1)$ & Work experience & Yes & 106(30.9) \\
\hline \multirow[t]{2}{*}{ Personality } & Extroversion & $206(60.1)$ & & No & $237(69.1)$ \\
\hline & Introversion & 137(39.9) & $\begin{array}{l}\text { Education of } \\
\text { parents }\end{array}$ & Postgraduate and above & $17(5.0)$ \\
\hline \multirow[t]{2}{*}{ Reading habits } & Yes & $278(81.0)$ & & $\begin{array}{l}\text { Undergraduate } \sim \text { Junior } \\
\text { College }\end{array}$ & $98(28.6)$ \\
\hline & No & $65(19.0)$ & & $\begin{array}{l}\text { Secondary school } \sim \text { high } \\
\text { school }\end{array}$ & $103(30.0)$ \\
\hline \multirow[t]{3}{*}{$\begin{array}{l}\text { Understanding of } \\
\text { CT }\end{array}$} & Know a lot & $30(8.7)$ & & $\begin{array}{l}\text { Junior high school and } \\
\text { below }\end{array}$ & $125(36.4)$ \\
\hline & A little idea & $250(72.9)$ & & & \\
\hline & Non & $63(78.4)$ & & & \\
\hline
\end{tabular}

Table 2 Medical doctoral students' critical thinking score $(\mathrm{N}=343)$

\begin{tabular}{lllll}
\hline Domain & Lowest score & Highest score & Mean & SD \\
\hline Total score & 215.00 & 369.00 & 292.43 & 28.95 \\
Truth-seeking & 14.00 & 60.00 & 38.13 & 6.36 \\
Open-thinking & 25.00 & 53.00 & 41.92 & 5.07 \\
Analyticity & 25.00 & 56.00 & 43.99 & 4.97 \\
Systematicity & 26.00 & 60.00 & 41.15 & 5.73 \\
Self-confidence & 15.00 & 60.00 & 40.53 & 6.37 \\
Inquisitiveness & 25.00 & 60.00 & 44.17 & 6.34 \\
Maturity & 10.00 & 60.00 & 42.54 & 6.66 \\
\hline
\end{tabular}

$N$ total number of medical doctoral students

investigated; $C T$ critical thinking 
Table 3 The number and composition ratio of the total score and traits of $\mathrm{CT}(\mathrm{N}=343)$

\begin{tabular}{lcccc}
\hline Critical thinking & \multicolumn{2}{c}{ Low score } & \multicolumn{2}{c}{ High score } \\
\cline { 2 - 5 } & Number & Ratio(\%) & Number & Ratio(\%) \\
\hline Total score & 107 & 31.2 & 4 & 1.2 \\
Truth-seeking & 201 & 58.6 & 8 & 2.3 \\
Open-thinking & 103 & 30.0 & 24 & 7.0 \\
Analyticity & 56 & 16.4 & 42 & 12.2 \\
Systematicity & 143 & 41.7 & 29 & 8.5 \\
Self-confidence & 150 & 43.7 & 27 & 7.9 \\
Inquisitiveness & 76 & 22.1 & 65 & 19.0 \\
Maturity & 95 & 27.7 & 46 & 13.4 \\
\hline
\end{tabular}

$N$ total number of medical doctoral students investigated; $C T$ critical thinking

Table 4 Personality and critical thinking scores [Mean(SD)]

\begin{tabular}{lcccc}
\hline & Extroversion(n=206) & Introversion(n=137) & $t$ & $P$ value \\
\hline Total score & $296.72(29.05)$ & $285.98(27.66)$ & 11.683 & 0.001 \\
Truth-seeking & $38.60(6.29)$ & $37.43(6.43)$ & 2.780 & 0.096 \\
Open-thinking & $42.29(4.97)$ & $41.35(5.19)$ & 2.847 & 0.092 \\
Analyticity & $44.33(4.95)$ & $43.46(4.96)$ & 2.566 & 0.110 \\
Systematicity & $41.88(5.63)$ & $40.05(5.72)$ & 8.594 & 0.004 \\
Self-confidence & $41.15(5.73)$ & $41.63(6.03)$ & 15.989 & $\square 0.001$ \\
Inquisitiveness & $44.97(6.38)$ & $42.98(6.10)$ & 8.270 & 0.004 \\
Maturity & $43.01(6.61)$ & $41.82(6.69)$ & 2.642 & 0.105 \\
\hline
\end{tabular}

Table 5 Reading habits and critical thinking scores [Mean(SD)]

\begin{tabular}{lcccc}
\hline & Have reading habit(n=278) & Non reading habit(n=65) & $t$ & $P$ value \\
\hline Total score & $295.95(28.13)$ & $277.38(27.73)$ & 23.062 & 0.000 \\
Truth-seeking & $38.44(6.11)$ & $36.82(7.24)$ & 3.455 & 0.064 \\
Open-thinking & $42.20(4.95)$ & $40.71(5.46)$ & 4.596 & 0.033 \\
Analyticity & $44.42(4.80)$ & $42.12(5.27)$ & 11.628 & 0.001 \\
Systematicity & $41.61(5.64)$ & $39.18(5.73)$ & 9.682 & 0.002 \\
Self-confidence & $41.36(5.79)$ & $37.02(7.50)$ & 26.283 & 0.000 \\
Inquisitiveness & $44.97(6.02)$ & $40.75(6.57)$ & 24.971 & 0.000 \\
Maturity & $42.95(6.09)$ & $40.78(8.52)$ & 5.650 & 0.018 \\
\hline
\end{tabular}

Table 6 Critical thinking scores of medical doctoral students in different interpersonal relations [Mean(SD)] 


\begin{tabular}{lccccccc}
\hline & $\begin{array}{c}\text { Very } \\
\text { easy(n=17) }\end{array}$ & Easy(n=178) & $\begin{array}{c}\text { Deal } \\
\text { with(n=107) }\end{array}$ & Difficult(n=35) & $\begin{array}{c}\text { Very } \\
\text { difficult(n=6) }\end{array}$ & F & $\mathrm{q}$ \\
\hline Total score & $304.06(36.10)$ & $298.16(29.32)$ & $285.07(26.37)$ & $286.94(17.39)$ & $252.50(31.52)$ & $7.921^{* *}$ & $5 \mathrm{vs} 1,2,3,4$, \\
Truth-seeking & $37.06(8.56)$ & $39.02(5.62)$ & $37.16(7.110$ & $37.31(4.73)$ & $37.00(11.51)$ & 1.816 & - \\
Open-thinking & $40.41(7.18)$ & $42.63(5.10)$ & $41.07(4.67)$ & $42.37(4.13)$ & $37.33(5.09)$ & $3.409^{*}$ & $5 \mathrm{vs} 2,4$ \\
Analyticity & $47.29(4.87)$ & $44.69(4.86)$ & $42.97(4.38)$ & $43.37(4.19)$ & $35.33(8.91)$ & $9.432^{* *}$ & $1 \mathrm{vs} 3,4 ;$ \\
& & & & & & $5 \mathrm{vs} 1,2,3,4 ;$ \\
Systematicity & $45.53(7.65)$ & $42.24(5.57)$ & $39.81(5.02)$ & $38.66(4.59)$ & $34.83(6.82)$ & $9.972^{* *}$ & $1 \mathrm{vs} 3,4 ;$ \\
& & & & & & $5 \mathrm{vs} 1,2,3,4 ;$ \\
Self- & $47.00(7.12)$ & $41.20(6.11)$ & $39.49(5.78)$ & $38.51(5.14)$ & $32.83(10.91)$ & $9.534^{* *}$ & $1 \mathrm{vs} 2,3,4 ;$ \\
confidence & & & & & & $5 \mathrm{vs} 1,2,3,4 ;$ \\
Inquisitiveness & $47.00(7.58)$ & $45.20(6.28)$ & $42.72(5.87)$ & $43.00(5.15)$ & $38.50(9.96)$ & $5.155^{* *}$ & $5 \mathrm{vs} 1,2$ \\
Maturity & $39.76(8.32)$ & $43.18(6.13)$ & $41.86(6.83)$ & $43.71(4.88)$ & $36.67(15.07)$ & $2.935^{*}$ & $5 \mathrm{vs} 2,3,4$ \\
\hline
\end{tabular}

$C T$ critical thinking; * $P<0.05$; ${ }^{* *} P<0.01$; - data unavailable or not applicable

Table 7 Related factors of critical thinking scores in medical doctoral students 


\begin{tabular}{|c|c|c|c|}
\hline Score of critical thinking & B & $95 \% \mathrm{CI}$ & $P$ \\
\hline Character & -7.28 & $(-13.02,-1.53)$ & 0.013 \\
\hline \multicolumn{4}{|l|}{ Extracurricular reading time } \\
\hline$\leq 7$ hour & 10.49 & $(3.02,17.96)$ & 0.006 \\
\hline 7-14hour & 15.80 & $(6.92,24.69)$ & 0.001 \\
\hline$\geq 14$ hour & 21.15 & $(12.58,29.71)$ & 0.000 \\
\hline \multicolumn{4}{|l|}{ Education background of parents } \\
\hline Undergraduate / Junior College & -14.69 & $(-29.12,-0.27)$ & 0.046 \\
\hline Secondary school / high school & -12.38 & $(-27.58,2.81)$ & 0.110 \\
\hline Junior high school and below & -15.39 & $(-30.57,-0.21)$ & 0.047 \\
\hline \multicolumn{4}{|l|}{ Work experience } \\
\hline Below 3 years & -.78 & $(-8.26,6.70)$ & 0.837 \\
\hline 3-5years & 3.90 & $(-8.79,16.60)$ & 0.546 \\
\hline Over 5 years & -3.22 & $(-18.45,12.00)$ & 0.677 \\
\hline Academic type & 0.89 & $(-5.16,6.94)$ & 0.772 \\
\hline Gender & 4.59 & $(-2.2,11.38)$ & 0.185 \\
\hline Domicile & -2.57 & $(-9.61,4.48)$ & 0.47 \\
\hline Marital status & -4.28 & $(-11.93,3.38)$ & 0.272 \\
\hline Cons & 297.48 & $*$ & 0.000 \\
\hline
\end{tabular}

